Research Article

\title{
Resumption of School amid the COVID-19 Pandemic: A Rapid Assessment of Knowledge, Attitudes, and Preventive Practices among Final-Year Senior High Students at a Technical Institute in Ghana
}

\author{
Stephen Dajaan Dubik $\mathbb{D}^{1,2}$ Kingsley E. Amegah, ${ }^{3}$ and Alhassan S. Adam ${ }^{4}$ \\ ${ }^{1}$ Department of Science, Tamale Technical Institute, Ghana Education Service, Tamale, Ghana \\ ${ }^{2}$ School of Allied Health Sciences, University for Development Studies, Tamale, Ghana \\ ${ }^{3}$ Department of Health Information, Hohoe Municipal Hospital, Hohoe, Ghana \\ ${ }^{4}$ Administration, Tamale Technical Institute, Ghana Education Service, Tamale, Ghana \\ Correspondence should be addressed to Stephen Dajaan Dubik; stephendubik@gmail.com
}

Received 10 September 2020; Revised 8 March 2021; Accepted 19 March 2021; Published 1 April 2021

Academic Editor: Lunthita M. Duthely

Copyright (C) 2021 Stephen Dajaan Dubik et al. This is an open access article distributed under the Creative Commons Attribution License, which permits unrestricted use, distribution, and reproduction in any medium, provided the original work is properly cited.

\begin{abstract}
Background. The COVID-19 pandemic has brought about significant challenges to Ghana's education system, leading to the closure of schools for months. On 31 May 2020, the government of Ghana took a bold decision based on expert advice to reopen schools for final-year students amid the COVID-19 pandemic. However, data for students' knowledge, attitudes, and practices towards COVID-19 are limited. We sought to investigate students' level of knowledge, attitudes, and practices towards COVID-19 at Tamale Technical Institute, Ghana. Methods. A cross-sectional study was conducted among 175 final-year students from June to August 2020. A validated questionnaire adapted from previous studies was distributed to the students in their various classes by the researchers. Data were analysed using descriptive statistics, analysis of variance, and multivariate logistic regression. All analyses were significant at a $p$ value of less than 0.05 . Results. The mean age of the study participants was 21.1 years $(\mathrm{SD}=2.67)$, with more males $(72.0 \%)$ than females participating in the study. The majority (69.7\%) of the students trust traditional media sources, i.e., television and radio to receive COVID-19-related information. Awareness about COVID-19 was high (98.3\%), and in total, $62.9 \%(n=110)$ had good knowledge, $58.3 \%(n=102)$ had positive attitudes, and $54.9 \%(n=96)$ had good practices towards COVID-19. Factors associated with knowledge were receiving education on COVID-19 (AOR $=0.23$; 95\% CI: 0.01, 0.55) and mother level of education ( $\mathrm{AOR}=0.13$; 95\% CI: 0.02, 0.66). Positive attitudes towards COVID-19 were $63 \%$ less likely among students who did not receive education on COVID-19 (AOR $=0.37 ; 95 \%$ CI: $0.15,0.90)$. Students who received education on COVID-19 exhibited good practice towards COVID-19 than students who did not receive education on COVID-19 ( $p=0.014)$. Conclusion. Final-year students of Tamale Technical Institute possess good knowledge, attitudes, and practices toward COVID-19. Our findings demonstrate the significant role of health education in improving students' knowledge, attitudes, and practices towards COVID-19. We recommend continuous and targeted health education to mitigate the widespread misconceptions about COVID-19 through the use of traditional media such as television and radio.
\end{abstract}

\section{Introduction}

The COVID-19 pandemic has devastated almost every part of the globe, creating economic, health, and educational crises. Originally from Wuhan, China, the novel coronavirus was declared a global pandemic by the WHO. To date, there are approximately 25 million laboratory-confirmed COVID19 cases, including 833,556, reported deaths globally [1].

In Ghana, the first two cases of COVID-19 were reported on 12 March 2020 involving two returnees from Norway and Turkey [2]. As of 25 August 2020, there were 43,949 confirmed cases of COVID-19 in Ghana with 270 deaths [3]. In 
response, the government of Ghana instituted several measures to contain the COVID-19 pandemic. These included a ban on social activities, closure of schools, closure of borders, lockdowns, and restriction of movement of people in Greater Accra and Ashanti regions. The education sector of Ghana came to a standstill with the closure of basic, senior high, and tertiary institutions [4]. Before the closure of schools on 15 March 2020, final-year students in senior high schools were preparing for their West Africa Senior School Certificate Examination (WASSCE) [4]. In consultation with teacher unions and other stakeholders in education, the government of Ghana directed the reopening of schools for final-year students to enable them write their respective exit examination [5]. For the students to adhere to national COVID-19 guidelines, the government of Ghana provided face masks and hand sanitizers to the final-year students on school resumption coupled with the fumigation and disinfection of the schools. However, data for senior high students' knowledge, attitudes, and practices, which can predict students' behaviour towards COVID-19 preventive measures are limited. We aimed to investigate the students' level of knowledge, attitudes, and practices towards COVID19.

Exploring the students' knowledge, attitudes, and practices towards COVID-19 could help design health promotion programs that will help address gaps in knowledge and attitudes of the students towards COVID-19. Furthermore, the study will provide insight into COVID-19-related preventive practices among students, which will be crucial in preparing school authorities in response to future infectious disease outbreaks.

\section{Materials and Methods}

2.1. Study Design and Area. The study was a descriptive cross-sectional study that was conducted among final-year students of Tamale Technical Institute from June to August 2020. Tamale Technical Institute is located in Tamale Technical University and has a final-year student population of two hundred and eighty-two (282).

The study population included all final-year students of the Institute who consented to participate in the study. The researchers approached the study participants in their various classes and invited them to participate in the study. Of 282 final-year students at Tamale Technical Institute, all of them were invited, and 175 participated (response rate of $62 \%)$. The questionnaires were distributed to the students in their various classes, which they answered under the guidance of the researchers. The study tool was adopted from previous studies [6-8]. Approval to conduct the study was granted by the Institute. The study process was completely anonymous, and no personal identifiers were used in the study.

\subsection{Study Variables}

2.2.1. Independent Variables. Demographic variables include age, sex, religion, origin of student, program of study, mother's level of education, father's level of education, heard about COVID-19, sources of COVID-19 information, and trust in information sources about COVID-19.

2.2.2. Dependent Variables. The outcome variables were knowledge, attitudes, and practices towards COVID-19.

Knowledge towards COVID-19 was assessed using a validated 18-item questionnaire adapted from previous studies $[6,8]$. The knowledge questionnaire covered areas concerning causes of COVID-19, signs and symptoms, the transmission of COVID-19, and treatment and prevention of COVID-19. A correct response was scored 1, while an incorrect response was scored 0 , with a higher score indicating a good level of knowledge. A mean score was calculated, and those students who scored above the mean mark were considered to have good knowledge of COVID19.

Attitudes toward COVID-19 were assessed using 6 statements with 5-point Likert items strongly, namely, disagree (SD), disagree (D), neutral $(\mathrm{N})$, agree $(\mathrm{A})$, and strongly disagree weighing $1,2,3,4$, and 5, respectively, for positive statements. One statement, "black race is protective toward COVID-19 disease," was reverse scored. A mean value was calculated, and those who scored above the mean value were considered to have a positive attitude towards COVID-19.

Practices towards COVID-19 were assessed using 5 statements with 4-point Likert responses, namely, always, usually, sometimes, and never. Always and usually were considered appropriate practices towards COVID-19 while sometimes and never were considered inappropriate practices towards COVID-19. The responses of the students were dichotomised as 1 (yes) for always and usually and 0 (no) for sometimes and never. One statement, "In recent days, have you gone to any crowded place?", was reverse scored. A mean value was calculated, and those who scored above the mean value were considered to have good practices towards COVID-19.

2.3. Data Analysis. The data were entered into SPSS version 20.0 and later exported to STATA 14.2 for further analysis. Descriptive statistics were used to present the results in text, tables, and figures. Means and standard deviations were calculated for numerical data, while frequencies and percentages were calculated for categorical data. Differences in knowledge, attitude, and practice were determined using $t$ tests and analysis of variance. Multivariate logistic regression was used to determine the association between the independent and dependent variables. All variables were declared significant at a $p$ value of less than 0.05 .

\section{Results and Discussion}

3.1. Sociodemographic Characteristics of the Study Participants. The mean age of the study participants was 21.1 years, ranging from 16 to 32 years. More males $(72.0 \%)$ than females participated in the study. Most (69.1\%) of the students were affiliated with the Islamic religion. Approximately $60 \%$ of the students intimate the fact that their father 
had no formal education, and $73.1 \%$ also responded that their mother had no formal education (Table 1).

An overwhelming majority (98.3\%) of the students have heard about COVID-19. Most (65.7\%) of the students indicated that they heard about COVID-19 through traditional media sources, i.e., TV/radio. Similarly, the majority of the students trust traditional media sources, i.e., TV/radio, to receive information related to COVID-19 (Table 1).

3.2. Knowledge of Students at Tamale Technical Institute towards COVID-19. Knowledge of the study participants towards COVID-19 is presented in Table 2. The study participants' highest correct responses were observed in three items, i.e., coronavirus transmission is increased in crowded places $(94.9 \%)$, coronavirus can be transmitted through the coughing and sneezing of the infected person $(94.3 \%)$, and regular wearing of face mask protects against the transmission of COVID-19 (94.3\%). The lowest score was seen in two knowledge items, i.e., eating or contacting wild animals would result in infection by the COVID-19 virus (25.7\%), and persons with COVID-19 cannot transfer the virus to others when a fever is not present (47.3\%) (Table 2). Generally, the mean knowledge score was 13.9 $(\mathrm{SD}=2.7)$ out of 18 , and overall, $62.9 \%(n=110)$ of the students had good knowledge of COVID-19.

Significant differences were observed among students who received education on COVID-19 and those who did not $(p<0.001)$ (Table 3). Students who did not receive education on COVID-19 were $77 \%$ less likely to have good knowledge on COVID-19 compared to students who had received education on COVID-19 (AOR $=0.23$; 95\% CI: $0.01,0.55$ ) (Table 4).

3.3. Attitudes of the Students towards COVID-19. Interestingly, about $49.7 \%$ of the students were of the view that black race is protective against COVID-19 disease. Additionally, the majority (74.3\%) of the students agree that wearing a well-fitting face mask helps in preventing COVID19 and that frequent washing of hands will prevent COVID$19(80 \%)$. Most (59.4\%) of the study participants agree that Ghana will win the fight against the COVID-19 virus, while most (50.3\%) of them generally agree that the government of Ghana is handling the COVID-19 health crisis very well (Figure 1).

The mean attitude score was $20.9(\mathrm{SD}=4.3)$ out of 30 , and overall, $58.3 \%(n=102)$ of the students had a positive attitude towards COVID-19. There was no statistically significant difference between the attitude mean scores of students towards COVID-19 ( $p>0.05)$ (Table 3). Students who did not receive education on COVID-19 were 63\% times less likely to have good attitudes towards COVID-19 compared to students who had received education on COVID-19 (AOR =0.37; 95\% CI: 0.15, 0.90) (Table 4).

3.4. Practices of Students at Tamale Technical Institute towards COVID-19. Approximately $86 \%$ of the students reported
TABle 1: Sociodemographic characteristics of the study participants.

\begin{tabular}{|c|c|c|}
\hline Independent variables & Frequency $n(175)$ & Percent \\
\hline Age; mean (SD), $\min -\max$ & $21.12(2.51), 16-32$ & - \\
\hline \multicolumn{3}{|l|}{ Age group (in years) } \\
\hline$<18$ & 5 & 2.9 \\
\hline $18-25$ & 161 & 92.0 \\
\hline $26-32$ & 9 & 5.1 \\
\hline \multicolumn{3}{|l|}{ Gender } \\
\hline Male & 126 & 72.0 \\
\hline Female & 49 & 28.0 \\
\hline \multicolumn{3}{|l|}{ Religious affiliation } \\
\hline Christianity & 54 & 30.9 \\
\hline Islam & 121 & 69.1 \\
\hline \multicolumn{3}{|l|}{ Origin of student } \\
\hline Northern Ghana & 162 & 92.6 \\
\hline Southern Ghana & 13 & 7.4 \\
\hline \multicolumn{3}{|l|}{ Program of study } \\
\hline Fashion and design & 29 & 16.6 \\
\hline Catering & 29 & 16.6 \\
\hline Building and construction & 15 & 8.6 \\
\hline Carpentry and joining & 17 & 9.7 \\
\hline Welding and fabrication & 12 & 6.9 \\
\hline Electrical engineering & 50 & 28.6 \\
\hline Automobile engineering & 10 & 5.7 \\
\hline Others $^{\mathrm{a}}$ & 13 & 7.4 \\
\hline \multicolumn{3}{|l|}{ Father's level of education } \\
\hline No formal education & 106 & 60.6 \\
\hline Basic level & 17 & 9.7 \\
\hline SHS level & 29 & 16.6 \\
\hline Tertiary level & 23 & 13.1 \\
\hline \multicolumn{3}{|l|}{ Mother's level of education } \\
\hline No formal education & 128 & 73.1 \\
\hline Basic level & 21 & 12.0 \\
\hline SHS level & 13 & 7.4 \\
\hline Tertiary level & 13 & 7.4 \\
\hline \multicolumn{3}{|l|}{ Heard about COVID-19 } \\
\hline Yes & 172 & 98.3 \\
\hline No & 3 & 1.7 \\
\hline \multicolumn{3}{|l|}{ Sources of COVID-19 information } \\
\hline WhatsApp & 10 & 5.7 \\
\hline Facebook & 22 & 12.6 \\
\hline TV/radio & 115 & 65.7 \\
\hline Teachers & 5 & 2.9 \\
\hline Friends/relatives & 7 & 4.0 \\
\hline Community announcement & 8 & 4.6 \\
\hline Websites of health organization & 8 & 4.6 \\
\hline \multicolumn{3}{|c|}{ Trust in information sources about COVID-19 } \\
\hline WhatsApp & 7 & 4.0 \\
\hline Facebook & 12 & 6.9 \\
\hline $\mathrm{TV} /$ radio & 122 & 69.7 \\
\hline Teachers & 2 & 1.1 \\
\hline Friends/relatives & 8 & 4.6 \\
\hline Community announcement & 4 & 2.3 \\
\hline Websites of health organization & 20 & 11.4 \\
\hline \multicolumn{3}{|l|}{ Received education about COVID-19 } \\
\hline Yes & 136 & 77.7 \\
\hline No & 39 & 22.3 \\
\hline
\end{tabular}

${ }^{\mathrm{a}}$ Other programmes of study include agric engineering, painting and decoration, and mechanical engineering. 
TABle 2: Knowledge of students at Tamale Technical Institute towards COVID-19.

\begin{tabular}{|c|c|}
\hline Items & $\begin{array}{c}\text { Correct } \\
\text { responses }\end{array}$ \\
\hline Rate (\%) & - \\
\hline COVID-19 is caused by a virus from the coronavirus family (yes) & 74.3 \\
\hline \multicolumn{2}{|l|}{ Signs and symptoms of COVID-19 } \\
\hline Cough (yes) & 93.7 \\
\hline Fever (yes) & 81.1 \\
\hline Headache (yes) & 76.0 \\
\hline Difficulty in breathing (yes) & 82.9 \\
\hline Muscle pain (yes) & 48.0 \\
\hline Running nose (yes) & 75.4 \\
\hline Coronavirus can be transmitted through the coughing and sneezing of the infected person (yes) & 94.3 \\
\hline Eating or contacting wild animals would result in infection by the COVID-19 virus (no) & 25.7 \\
\hline Persons with COVID-2019 cannot transfer the virus to others when a fever is not present (no) & 47.3 \\
\hline Coronavirus enters into humans' body through the mouth, nose, and eyes (yes) & 89.7 \\
\hline Coronavirus transmission is increased in crowded places (yes) & 94.9 \\
\hline It is not necessary for children and young adults to take measures to prevent the infection by the COVID-19 virus (no) & 65.1 \\
\hline There is currently no effective treatment or vaccine for COVID-19 (yes) & 67.4 \\
\hline $\begin{array}{l}\text { To prevent the infection by COVID-19, individuals should avoid going to crowded places such as markets, bus station, } \\
\text { and funerals (yes) }\end{array}$ & 91.4 \\
\hline The disease can be prevented through regular handwashing and personal hygiene (yes) & 93.1 \\
\hline Regular wearing of face mask protects against the transmission of COVID-19 (yes) & 94.3 \\
\hline $\begin{array}{l}\text { The disease can be prevented through no close contacts such as handshakes or kissing, not attending meetings, and } \\
\text { frequent hand disinfection (yes) }\end{array}$ & 89.7 \\
\hline
\end{tabular}

TABLE 3: Differences in the level of knowledge, attitudes, and practices towards COVID-19 according to students' characteristics.

\begin{tabular}{|c|c|c|c|c|}
\hline Independent variables & $n(\%)$ & $\begin{array}{c}\text { Knowledge (score range: } 5-18) \\
\text { Mean (SD) }\end{array}$ & $\begin{array}{c}\text { Attitude (score range: } 8-30 \text { ) } \\
\text { Mean (SD) }\end{array}$ & $\begin{array}{c}\text { Practice (score range: } 0-5 \text { ) } \\
\text { Mean (SD) }\end{array}$ \\
\hline \multicolumn{5}{|l|}{ Age group (in years) } \\
\hline$<18$ & $5(2.9)$ & $13.2(4.02)$ & $21.4(7.06)$ & $2.6(1.14)$ \\
\hline $18-25$ & $161(92.0)$ & $13.9(2.66)$ & $21.0(4.24)$ & $3.0(1.20)$ \\
\hline $26-32$ & $9(5.1)$ & $14.0(3.57)$ & $20.6(3.40)$ & $2.8(1.09)$ \\
\hline \multicolumn{5}{|l|}{ Gender } \\
\hline Male & $126(72.0)$ & $13.8(2.80)$ & $20.9(4.25)$ & $2.9(1.27)$ \\
\hline Female & $49(28.0)$ & $14.1(2.36)$ & $21.2(4.37$ & $3.2(0.92)$ \\
\hline \multicolumn{5}{|l|}{ Religious affiliation } \\
\hline Christianity & $54(30.9)$ & $14.2(2.40)$ & $21.5(3.90)$ & $3.3(1.07)^{*}$ \\
\hline Islam & $121(69.1)$ & $13.7(2.86)$ & $20.7(4.42)$ & $2.9(1.22)$ \\
\hline \multicolumn{5}{|l|}{ Origin of student } \\
\hline Northern & $162(92.6)$ & $13.9(2.70)$ & $20.8(4.29)$ & $3.0(1.20)$ \\
\hline Southern & $13(7.4)$ & $13.8(2.30)$ & $22.5(3.84)$ & $3.3(1.03)$ \\
\hline \multicolumn{5}{|l|}{ Program of study } \\
\hline Fashion and design & $29(16.6)$ & $14.3(2.36)$ & $21.1(3.52)$ & $3.0(1.25)$ \\
\hline Catering & $29(16.6)$ & $14.2(2.64)$ & $21.2(4.90)$ & $3.4(0.78)$ \\
\hline Building and construction & $15(8.6)$ & $14.1(2.13)$ & $19.6(5.03)$ & $3.2(1.42)$ \\
\hline Carpentry and joining & $17(9.7)$ & $13.1(2.66)$ & $20.2(4.49)$ & $3.2(1.51)$ \\
\hline Welding and fabrication & $12(6.9)$ & $13.4(3.70)$ & $23.2(4.75)$ & $2.3(1.44)$ \\
\hline Electrical engineering & $50(28.6)$ & $13.9(2.88)$ & $20.6(3.54)$ & $2.9(0.95)$ \\
\hline Automobile engineering & $10(5.7)$ & $12.8(3.55)$ & $22.0(5.87)$ & $3.0(1.33)$ \\
\hline Others $^{\mathrm{a}}$ & $13(7.4)$ & $13.9(2.33)$ & $21.1(4.01)$ & $2.8(1.46)$ \\
\hline \multicolumn{5}{|l|}{ Father's level of education } \\
\hline No formal education & $106(60.6)$ & $13.9(2.35)$ & $20.7(4.33)$ & $2.9(1.18)$ \\
\hline Basic level & $17(9.7)$ & $13.8(3.56)$ & $21.0(4.82)$ & $2.8(1.20)$ \\
\hline SHS level & $29(16.6)$ & $14.0(3.05)$ & $20.4(3.53)$ & $3.3(1.07)$ \\
\hline Tertiary level & $23(13.1)$ & $13.6(3.38)$ & $22.8(4.21)$ & $3.3(1.32)$ \\
\hline \multicolumn{5}{|l|}{ Mother's level of education } \\
\hline No formal education & $128(73.1)$ & $14.1(2.57)$ & $20.9(4.31)$ & $3.0(1.20)$ \\
\hline Basic level & $21(12.0)$ & $13.0(3.79)$ & $20.0(4.97)$ & $2.8(1.08)$ \\
\hline
\end{tabular}


TABle 3: Continued.

\begin{tabular}{lcccc}
\hline Independent variables & $n(\%)$ & $\begin{array}{c}\text { Knowledge (score range: 5-18) } \\
\text { Mean (SD) }\end{array}$ & $\begin{array}{c}\text { Attitude (score range: 8-30) } \\
\text { Mean (SD) }\end{array}$ & $\begin{array}{c}\text { Practice (score range: 0-5) } \\
\text { Mean (SD) }\end{array}$ \\
\hline SHS level & $13(7.4)$ & $13.2(1.99)$ & $22.8(3.41)$ & $3.2(1.24)$ \\
Tertiary level & $13(7.4)$ & $14.1(2.81)$ & $21.3(3.04)$ & $3.4(1.19)$ \\
\hline Received education about COVID-19 & & & \\
Yes & $136(77.7)$ & $14.6(2.69)^{*}$ & $21.1(4.25)$ & $3.1(1.16)^{*}$ \\
No & $39(22.3)$ & $13.7(2.48)$ & $20.4(4.36)$ & $2.6(1.21)$ \\
\hline
\end{tabular}

Note. ${ }^{*}$ Significant differences $(p<0.05)$.

TABle 4: Factors associated with knowledge, attitudes, and practices among students at Tamale Technical Institute.

\begin{tabular}{|c|c|c|c|c|c|c|}
\hline \multirow{2}{*}{ Independent variables } & \multicolumn{2}{|c|}{ Knowledge } & \multicolumn{2}{|c|}{ Attitude } & \multicolumn{2}{|c|}{ Practice } \\
\hline & AOR (95\% CI) & $p$ value & $\operatorname{AOR}(95 \% \mathrm{CI})$ & $p$ value & AOR $(95 \%$ CI) & $p$ value \\
\hline \multicolumn{7}{|l|}{ Age group (in years) } \\
\hline$<18$ & Ref. & - & - & - & $0.79(0.07-8.41)$ & 0.842 \\
\hline $18-25$ & $0.11(0.01-1.73)$ & 0.118 & $0.96(0.10-9.71)$ & 0.974 & Ref. & - \\
\hline $26-32$ & $0.24(0.01-5.36)$ & 0.366 & $1.20(0.08-18.37)$ & 0.894 & $1.36(0.28-6.65)$ & 0.700 \\
\hline \multicolumn{7}{|l|}{ Gender } \\
\hline Male & Ref. & - & - & - & Ref. & - \\
\hline Female & $0.73(0.17-3.15)$ & 0.673 & $0.70(0.18-2.64)$ & 0.594 & $1.24(0.3-5.14)$ & 0.766 \\
\hline \multicolumn{7}{|l|}{ Religion } \\
\hline Christianity & Ref. & - & - & - & $1.39(0.58-3.32)$ & 0.459 \\
\hline Islam & $0.68(0.28-1.60)$ & 0.374 & $0.92(0.41-2.08)$ & 0.842 & Ref. & \\
\hline \multicolumn{7}{|l|}{ Origin of student } \\
\hline Northern zone & Ref. & - & - & - & - & - \\
\hline Southern zone & $1.72(0.37-7.95)$ & 0.488 & $4.20(0.90-19.72)$ & 0.069 & $2.63(0.46-14.83)$ & 0.275 \\
\hline \multicolumn{7}{|l|}{ Program of study } \\
\hline Fashion and design & Ref. & - & - & - & $1.21(0.33-4.35)$ & 0.774 \\
\hline Catering & $0.91(0.24-3.43)$ & 0.885 & $1.46(0.40-5.29)$ & 0.568 & $3.73(0.55-25.31)$ & 0.178 \\
\hline Building and construction & $1.06(0.19-5.85)$ & 0.947 & $0.38(0.08-1.86)$ & 0.234 & $1.77(0.44-7.14)$ & 0.425 \\
\hline Carpentry and joining & $0.33(0.07-1.63)$ & 0.175 & $0.27(0.06-1.25)$ & 0.094 & $1.24(0.37-4.16)$ & 0.729 \\
\hline Welding and fabrication & $0.47(0.08-2.70)$ & 0.399 & $4.66(0.63-34.15)$ & 0.130 & $0.86(0.22-3.37)$ & 0.828 \\
\hline Electrical engineering & $0.78(0.20-3.10)$ & 0.729 & $0.53(0.15-1.92)$ & 0.338 & Ref. & - \\
\hline Automobile engineering & $0.77(0.12-5.00)$ & 0.782 & $1.03(0.16-6.59)$ & 0.977 & $2.05(0.42-10.05)$ & 0.375 \\
\hline Others & $1.34(0.24-7.33)$ & 0.736 & $0.72(0.15-3.39)$ & 0.677 & $1.14(0.29-4.55)$ & 0.848 \\
\hline \multicolumn{7}{|l|}{ Father's level of education } \\
\hline No formal education & Ref. & - & - & - & - & - \\
\hline Basic level & $1.49(0.35-6.32)$ & 0.592 & $0.49(0.12-1.94)$ & 0.306 & $0.86(0.21-3.51)$ & 0.837 \\
\hline SHS level & $2.04(0.68-6.18)$ & 0.205 & $0.50(0.18-1.39)$ & 0.181 & $2.22(0.71-6.94)$ & 0.171 \\
\hline Tertiary level & $1.46(0.45-4.67)$ & 0.527 & $2.13(0.66-6.88)$ & 0.206 & $1.23(0.39-3.89)$ & 0.721 \\
\hline \multicolumn{7}{|l|}{ Mother's level of education } \\
\hline No formal education & Ref. & - & - & - & - & - \\
\hline Basic level & $0.53(0.17-1.72)$ & 0.291 & $1.28(0.41-4.01)$ & 0.674 & $1.05(0.33-3.37)$ & 0.938 \\
\hline SHS level & $0.13(0.02-0.66)$ & 0.014 & $1.75(0.34-9.00)$ & 0.502 & $0.55(0.1-3.08)$ & 0.498 \\
\hline Tertiary level & $0.70(0.16-3.06)$ & 0.632 & $0.89(0.21-3.71)$ & 0.875 & $1.26(0.26-6.14)$ & 0.771 \\
\hline \multicolumn{7}{|c|}{ Received education on COVID-19 } \\
\hline Yes & Ref. & - & - & - & - & - \\
\hline No & $0.23(0.01-0.55)$ & 0.001 & $0.37(0.15-0.90)$ & 0.029 & $0.49(0.21-1.14)$ & 0.097 \\
\hline
\end{tabular}

$\mathrm{AOR}=$ adjusted odds ratio.

having never gone to a crowded place due to the COVID-19 outbreak. Most always worn a mask while leaving home (61.1\%), wash hands regularly than usual (76.6\%), and avoided people coughing and sneezing (57.1\%) (Figure 2). The students' mean practices score was $3.0(\mathrm{SD}=1.19)$, and overall, more than half $(68 \%, n=119)$ had good practices towards COVID19. There was a statistically significant difference between the practice mean scores of students towards COVID-19 based on their religious affiliation $(p=0.039)$ and education received about COVID-19 $(p=0.014)$ (Table 3).

\section{Discussion}

To the best of our knowledge, this is the first study examining senior high students' knowledge, attitudes, and practices towards COVID-19 in Ghana. In this study, an overwhelming 


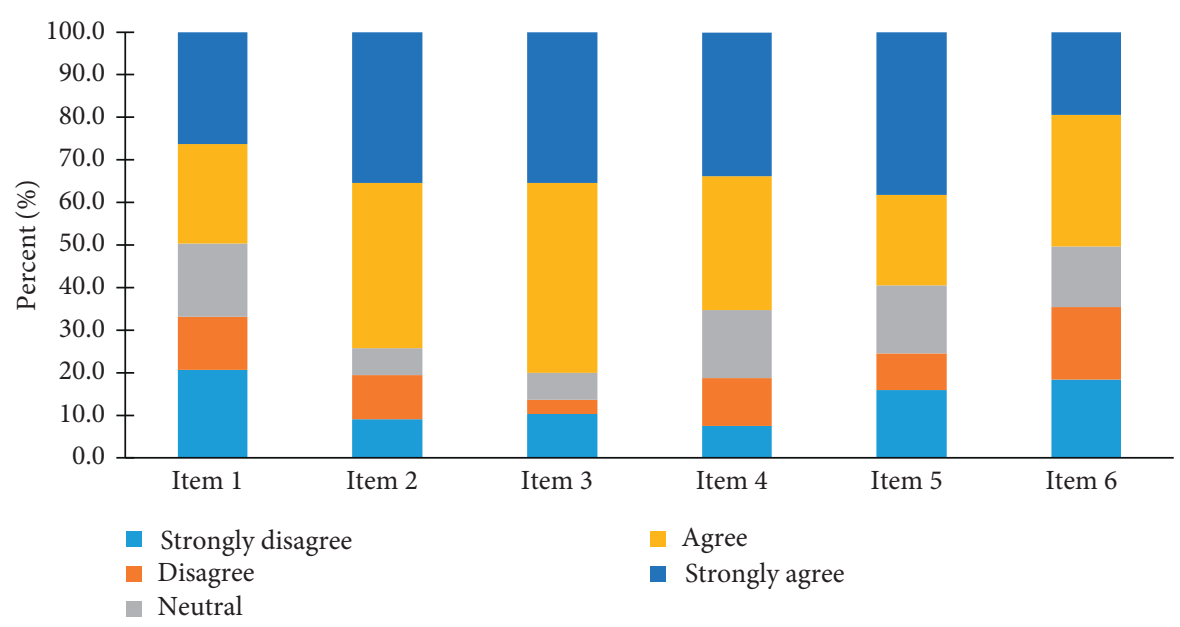

Figure 1: Attitudes of students at Tamale Technical Institute towards COVID-19.

\begin{tabular}{lc}
\hline No. & Items (key) \\
\hline 1 & Black race is protective toward COVID-19 disease \\
2 & Wearing a well-fitted face mask helps in preventing COVID-19 \\
3 & Frequent washing of hands will prevent you from getting COVID-19 \\
4 & COVID-19 virus will successfully be controlled \\
6 & Ghana will win the fight against the COVID-19 virus \\
\hline
\end{tabular}

\begin{tabular}{lc}
\hline No. & Items (key) \\
\hline 1 & In recent days, have you gone to any crowded place? \\
2 & In recent days, I have refrained from shaking hands \\
3 & In recent days, I have worn mask when leaving home \\
4 & In recent days, I wash my hands regularly than usual \\
5 & In recent days, I avoided people with cough and sneezing \\
\hline
\end{tabular}

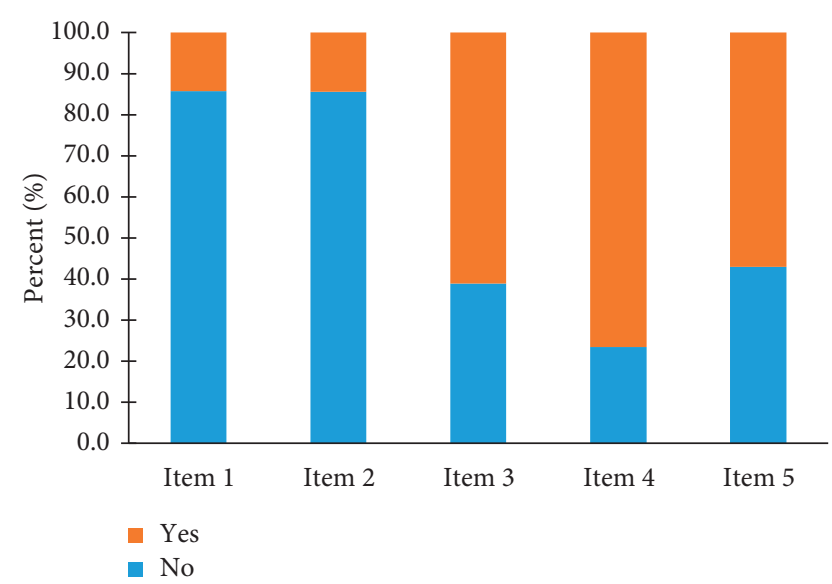

Figure 2: Practices of students at Tamale Technical Institute towards COVID-19.

majority of the students have ever heard about COVID-19. This is consistent with similar studies where they found high awareness about COVID-19 $[9,10]$. The high awareness in this study may be due to the widespread campaigns and education about COVID-19 in Ghana. In contrast with this study, where most of the students heard about COVID-19 through TV/radio, children in Cambodia heard about COVID-19 through Facebook [9]. Television remains an important source of knowledge about COVID-19 among secondary students in Italy [11]. This demonstrates the crucial role of traditional media in informing Ghanaians about the COVID-19 pandemic. Health promotion programs that seek to educate students about COVID-19 and other infectious diseases should consider TV/radio medium. A large majority of the students indicated that they trust $\mathrm{TV} /$ radio to receive COVID-19-related information. This is also supported by a similar study in Cambodia, where most of the children indicated that they trust TV to receive information about COVID-19 [9].

Overall, the students had a good level of knowledge towards COVID-19. This is in line with previous studies that found a good level of knowledge towards COVID-19 $[6,10,12,13]$. This may be because a vast majority of the study participants have ever received education on COVID-19. Health education plays a critical role in improving secondary students' knowledge, attitudes, and practices towards COVID-19 [14]. Although the students had good knowledge 
about COVID-19, knowledge gaps/misconceptions were observed, where most of the students indicated that eating or contacting wild animals would result in infection by the COVID-19 virus and that persons with COVID-19 could not transfer the virus to others when a fever was not present. This varies from what has been reported in similar studies where the majority disagree that eating or contacting wild animals would result in infection by the COVID-19 virus $[6,8,10]$. There is the need for intensification of health education to debunk these held misconceptions about COVID-19. Multivariate analysis revealed that good knowledge of COVID-19 was less likely among students who did not receive education on COVID-19 compared to students who received education on COVID-19. The effect of teaching on improving COVID19 knowledge has been reported among secondary students [15].

We found that the majority of the students reported positive attitudes towards COVID-19. Positive attitudes towards COVID-19 have been reported by previous studies in China [16], Malaysia [8], and Ethiopia [17]. Most of the students were of the view that frequent washing of hands prevents COVID-19. This is also the view of income-poor households in the Philippines, where most of the study participants identified handwashing as a preventive measure against the COVID-19 virus [10]. This will crucially impact the handwashing behaviour of the students due to their recognition that frequent handwashing prevents COVID-19. Generally, most of the students agree that Ghana will win the fight against the COVID-19 virus and that the government of Ghana is handling the COVID-19 health crisis very well. This is also the view of the public in Malaysia, where most of them had confidence in their country to win the battle against COVID-19 and that their government is handling the COVID-19 health crisis very well [8]. Indeed, the government of Ghana has put up several preventive measures to combat the COVID-19 pandemic [4]. Analysis of variance revealed no differences in students' attitudes by demographic variables. A study conducted in India also found no significant differences in students' demographic variables [18].

The majority of the students had good preventive practices towards the COVID-19 pandemic. This agrees with previous studies in which the study population reports a good level of preventive practices [10-12]. Our findings contradict a systematic review by Bhagavathula and colleagues, in which they reported a widespread lack of knowledge, attitudes, and preventive practices towards COVID-19 [19]. Most of the students have avoided going to crowded places in recent days as a precautionary measure towards the COVID-19 pandemic. This is supported by a previous study in China [12] and India [20] but contradicts another study in the Philippines where a few of the study samples identified avoiding the crowd as a preventive measure [10]. Also, most of the study participants regularly wash their hands as a preventive measure against the COVID-19 pandemic. A similar study among medical students in India reported an increase in the frequency of handwashing under the influence of COVID-19 [18]. Most of the students reported always wearing a mask when leaving home in recent days. This is in line with previous studies where most of the study participants reported wearing masks when leaving home $[6,10,20]$. In other jurisdictions, wearing masks was suboptimal [19]. Wearing of masks as a preventive measure against COVID-19 has been recommended by the WHO [21]. Students who received education on COVID-19 exhibited good practice towards COVID-19 than students who did not receive education on COVID-19. This demonstrates the crucial role of health education in improving preventive practices of the students towards COVID-19.

The study has limitations. The study was limited to one senior high school in Ghana; secondarily, recall of preventive practices could lead to bias. We recommend a large-scale study to assess knowledge, attitudes, and practices of senior high students towards COVID-19 in Ghana.

\section{Conclusion}

Final-year students of Tamale Technical Institute exhibited a good level of knowledge, attitudes, and practices towards COVID-19 but with some gaps that need to be addressed in relation to some misconceptions held by the students about aspects of knowledge and attitudes towards COVID-19. We recommend continuous and targeted health education to mitigate the widespread misconceptions about COVID-19. Furthermore, COVID-19 risk communication strategies targeting senior high students should consider traditional media sources to reach this group of audience.

\section{Data Availability}

The data used to support the findings of this study are available from the corresponding author upon reasonable request.

\section{Conflicts of Interest}

The authors declare no conflicts of interest with regard to this paper.

\section{Acknowledgments}

Our appreciation goes to the final-year students of Tamale Technical Institute and the school authorities.

\section{References}

[1] WHO, "WHO coronavirus disease (COVID-19) dashboard," https://covid19.who.int/.

[2] Ministry of Health, Ghana Confirm Two Cases of COVID-19, Ghana Health Service, Accra, Ghana, 2020.

[3] Ghana health service, "COVID-19 update," 2020, https:// ghanahealthservice.org/covid19/.

[4] 2020, Ghana closes schools, bans gatherings over coronavirus. Available online from https://medicalxpress.com/news/202003-ghana-schools-coronavirus.html.

[5] University World News, "Universities to reopen in mid-June to final-year students," 2020, https://www.universityworldne ws.com/post.php?story=20200601 12235883\#: :text=Ghana's \%20universities\%20and\%20schools\%20are,Dankwa\%20Akuf o\%2DAddo\%20has\%20said. 
[6] R. Olum, G. Chekwech, G. Wekha, D. R. Nassozi, and F. Bongomin, "Coronavirus disease-2019: knowledge, attitude, and practices of health care workers at makerere university teaching hospitals, Uganda," Frontiers in Public Health, vol. 8, p. 181, 2020.

[7] M. H. Taghrir, R. Borazjani, and R. Shiraly, "COVID-19 and Iranian medical students; a survey on their related-knowledge, preventive behaviors and risk perception," Archives of Iranian Medicine, vol. 23, no. 4, pp. 249-254, 2020.

[8] A. A. Azlan, M. R. Hamzah, T. J. Sern, S. H. Ayub, and E. Mohamad, "Public knowledge, attitudes and practices towards COVID-19: a cross-sectional study in Malaysia," PLoS One, vol. 15, no. 5, p. e0233668, 2020.

[9] Save the Children, "Understanding knowledge, attitudes, and practices of children about COVID-19," 2020, https:// resourcecentre.savethechildren.net/library/understandingknowledge-attitudes-and-practices-children-about-covid-19.

[10] L. L. Lau, N. Hung, D. J. Go et al., "Knowledge, attitudes and practices of COVID-19 among income-poor households in the Philippines: a cross-sectional study," Journal of Global Health, vol. 10, no. 1, 2020.

[11] M. Dilucca and D. Souli, "Knowledge, attitude and practice of secondary school students toward COVID-19 epidemic in Italy: a cross selectional study," bioRxiv, 2020.

[12] B.-L. Zhong, W. Luo, H.-M. Li et al., "Knowledge, attitudes, and practices towards COVID-19 among Chinese residents during the rapid rise period of the COVID-19 outbreak: a quick online cross-sectional survey," International Journal of Biological Sciences, vol. 16, no. 10, pp. 1745-1752, 2020.

[13] R. Pal, U. Yadav, S. Grover, B. Saboo, A. Verma, and S. K. Bhadada, "Knowledge, attitudes and practices towards COVID-19 among young adults with type 1 diabetes mellitus amid the nationwide lockdown in india: a cross-sectional survey," Diabetes Research and Clinical Practice, vol. 166, p. 108344, 2020.

[14] E. T. Baloran, "Knowledge, attitudes, anxiety, and coping strategies of students during COVID-19 pandemic," Journal of Loss and Trauma, vol. 25, no. 8, pp. 635-642, 2020.

[15] M. M. A. Ayed, T. M. Mahmoud, and F. E. Z. Kamal, "Impact of teaching program regarding COVID-19 on knowledge, attitudes, practices among student," Pediatric Nursing, 2020.

[16] Y. Peng, C. Pei, Y. Zheng et al., "A cross-sectional survey of knowledge, attitude and practice associated with COVID-19 among undergraduate students in China," BMC Public Health, vol. 20, no. 1, pp. 1-8, 2020.

[17] Y. A. Aynalem, T. Y. Akalu, B. Gebresellassie, N. T. Sharew, and W. S. Shiferaw, Assessment of Undergraduate Student Knowledge, Practices, and Attitude towards COVID-19, Debre Berhan University, Ethiopia, 2020.

[18] S. Maheshwari, P. K. Gupta, R. Sinha, and P. Rawat, "Knowledge, attitude, and practice towards coronavirus disease 2019 (COVID-19) among medical students: a cross-sectional study," Journal of Acute Disease, vol. 9, no. 3, pp. 100-104, 2020.

[19] A. S. Bhagavathula, W. A. Aldhaleei, J. Rahmani, and J. Khubchandani, "Knowledge, attitude, perceptions and practice towards COVID-19: a systematic review and metaanalysis," medRxiv, 2020.

[20] B. Srivastava and P. B. Reddy, "Assessment of KAP (Knowledge, Attitude and Practice) of university students towards prevention of COVID-19," International Journal of Biological Innovations, 2020.

[21] World Health Organization, Advice on the Use of Masks in the Context of COVID-19: Interim Guidance, 5 June 2020 (No. WHO/2019-nCov/IPC_Masks/2020.4), World Health Organization, Geneva, Switzerland, 2020. 